
D. BLEINER
P. GASSER

\title{
Structural features of laser ablation particulate from Si target, as revealed by focused ion beam technology
}

EMPA - Swiss Federal Laboratories for Materials Testing and Research, Ueberlandstrasse 129, 8600 Duebendorf, Switzerland

\section{Received: 1 October 2003/Accepted: 22 January 2004 Published online: 26 July 2004 • (C) Springer-Verlag 2004}

ABSTRACT Heterogeneity in laser-induced particle structures was investigated by scanning electron microscopy (SEM) and transmission electron microscopy (TEM) of individual particles micro-machined using focused ion beam (FIB). The primary particle size distribution spanned over three orders of magnitude, i.e., in the range $10 \mathrm{~nm}-10 \mu \mathrm{m}$ with few larger secondary objects. The particulate larger than $0.5 \mu \mathrm{m}$ often resulted from particle-particle aggregation, mostly upon a spherical core, seldom in chain-like structures. The core of these fractal aggregates was found to be polycrystalline. The heterogeneity of the particles with respect to structure and chemistry is surely of importance for elemental analysis using laser ablation as sample introduction technique.

PACS 39.30.+w; 61.46.+w; 81.20.Rg

\section{1}

\section{Introduction}

Laser ablation inductively coupled plasma mass spectrometry (LA-ICP MS) is based on the analytical information contained in and transported by laser-induced particles to the plasma mass spectrometer. Many researchers have dedicated efforts to investigate the influence of several operating parameters on the analytical results, like for instance the wavelength, pulse width, beam profile, cell geometry and how to optimise them [1-10]. The mechanism of formation and transport of the particles, the size distribution and the transport efficiency as well as the efficiency of thermal decomposition in the ICP are still debated.

Si wafers are technologically relevant samples and the possibility to have access to the spatial distribution of trace elements in them using LA - ICPMS is the driving force of this study. The aim of this work was to investigate the structure of laser ablated particles at relatively high fluence, and the particle behaviour inside the ablation chamber.

\section{2}

\section{Experimental}

Si wafer with a surface $100 \mathrm{~nm}$ multi-elemental layer (i.e. Ba, Sr, Ti, Pt, Rh) was ablated for $30 \mathrm{~s}$, using an in-house modified PE $320 \mathrm{Nd}$ : YAG laser sampler, operated at the frequency-quadrupled wavelength $(266 \mathrm{~nm})$, with

Fax: +41-1/821-62-44, E-mail: davide.bleiner@empa.ch a pulse energy of $4 \pm 0.2 \mathrm{~mJ}$ resulting in a fluence of approx. $50 \mathrm{~J} / \mathrm{cm}^{2}$. Argon and helium were used as carrier gases at a flow of $0.9 \mathrm{l} / \mathrm{min}$ through the chamber (standard operating conditions for ICP MS analysis). The sample was micro-machined with a Strata DB 235 dual beam (DB) focused ion beam (FIB) workstation ('FEI company, USA') that incorporates a FIB and a scanning electron microscope (SEM) column tilted to each other at an angle of $52^{\circ}$. The FIB column is adjustable from $1 \mathrm{pA}$ to $20000 \mathrm{pA}$ at $30 \mathrm{kV}$ with a specified resolution of $7 \mathrm{~nm}$, as given by the manufacturer. The instrument is equipped with four secondary electron and ion detectors. The workstation has a digital patterning generator and four gas injection systems (GIS) for deposition and specific etching processes. The transmission electron microscope (TEM) specimens were prepared by milling an electron-transparent sample (e.g., $20 \mu \mathrm{m}$ long, $5 \mu \mathrm{m}$ wide and $100 \mathrm{~nm}$ thick) out of a bulk sample including the particle of interest. A Philips CM 30 TEM operated at an acceleration voltage at $200 \mathrm{kV}$ was used to study the microstructure.

\section{$3 \quad$ Results and discussion}

Figure 1 shows a survey of the ablated particles around the ablation site. The ablation crater is characterised

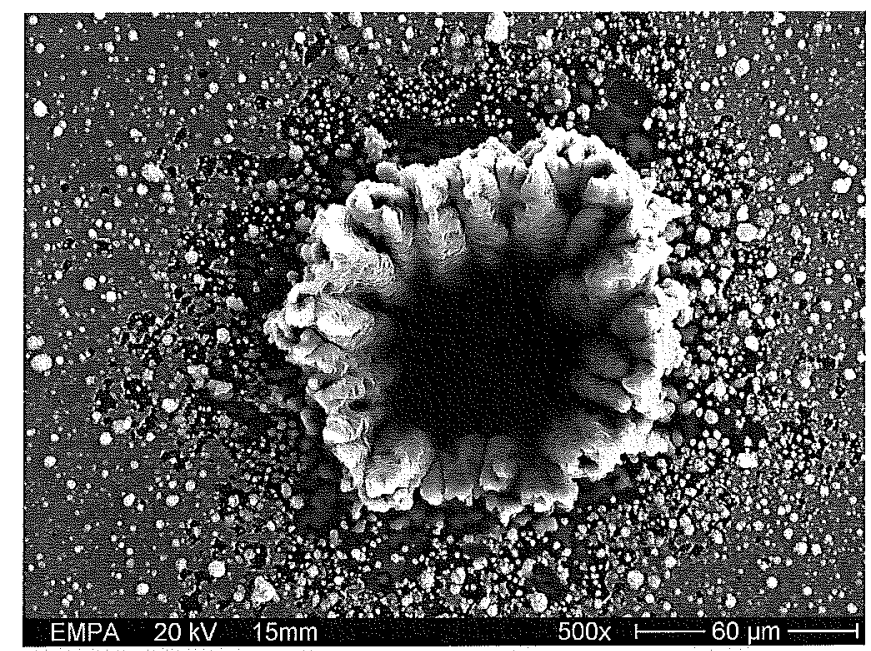

FIGURE 1 Top-view of one ablation crater. Hydrodynamic instability favours the elevation of the crater rim. Ablation products are distributed around the pit. In proximity to the irradiated spot the surface layer has been thermally mobilised 
by a pronounced wall of $40 \mu \mathrm{m}$ height (He) or $50 \mu \mathrm{m}$ (Ar), induced by extensive hydrodynamic instability of the sample at the spot rim. The dimensions of the ejected particulate span over three orders of magnitude, from a few tens of $\mathrm{nm}$ up to $10 \mu \mathrm{m}$. Primary particles are mostly well-rounded, and secondary products result from aggregation by deposition of nano-particles upon micro-particles. In Fig. 2a, details of the region close to the crater wall are shown. Particles as large as $9-10 \mu \mathrm{m}$ were observed as individual droplets or fractal aggregates. These fractal aggregates negatively affect the analytical determination in two ways. Firstly, they are not efficiently transported from the sample chamber to the ICP MS. Secondly, their atomisation in the plasma source will not be complete, leading to loss of signal. The region close to the crater, directly outside the irradiated spot, experienced thermal stress as shown in Fig. 2b. Here the surface multielemental layer has been thermally mobilised, vaporised during the irradiation across an aureole $10 \mu \mathrm{m}$ wide around the crater. 'Remote' sampling, i.e. sample removal not specific to the ablation spot, was a consequence of lateral thermal transport, typical of 'ns' ablation. The $10 \mu \mathrm{m}$ aureole of thermal stress suggests a "thermal transport" coefficient of approximately $10^{3} \mathrm{~cm}^{-1}$, which is several orders of magnitude lower than the absorption coefficient of Si at $266 \mathrm{~nm}$ [11]. Figure 2c shows melt droplets as large as $1 \mu \mathrm{m}$ scattered about. These rounded particles adhere firmly to the sample surface or can capture fine particulate from the gas, so inducing losses in the transported ensemble. Depending on the moment of deposition, these spherical particles experience longer or shorter surface accretion by nano-particles deposition. This ageing process contributes to the evolution of the particle outer structure from a smooth surface into a fluffy one. Figure $2 \mathrm{c}$ shows primary particles deposited at different times during the ablation experiments so that different ageing is translated into different extent of surface growth. This image also allows one to rule out the hypothesis that the fluffy structure is due to thermal shock of the particles upon cooling. Figure $2 \mathrm{~d}$ presents a magnification of the external fractal surface of one of these accreted particles whose surface nano-particulate is known to be enriched in volatile elements [12]. On the background the nano-particulate is densely covering the sample surface. The fractal dimension [13] of aggregated particles was determined to be in the range $D_{\mathrm{f}}=1.39-1.86$, depending on particle ageing.

Figure 3 shows the structure of particles in different ambient gases, cross-cut using FIB. In Fig. 3a the SEM image was taken after the particle was stabilised to the floor using the GIS, so the outer mass is artificial Pt coating (this is not present in Fig. 3b-d taken in $\mathrm{Ar}, \mathrm{He}, \mathrm{N}_{2}$ ambient). In LAICP MS argon or helium is routinely used as a carrier gas, so there is great interest in the particle characteristics of these gases. For comparison, Fig. 3d shows the particle structure from ablation in nitrogen. The particle in air is characterised by a rounded core and an outer fluffy corona aftergrowth. The core is oblate due to the impact onto the surface. After settling, nano-particulate present in the ablation chamber volume deposited progressively onto the surface. The outer corona thins out toward the floor where it is totally absent. The diffusion in the gas volume influences the particle concentration profile in the ablation cell and so also the growth rate of the surfaces. High growth rates are obtained for high concentration regions. In recent works $[10,14]$ it was shown that particle concentration inside the cell volume is more uniform in helium ambient than in argon, due to physical properties of the gases. Among the two, Ar enhances particle-wall reaction. Thus, diffusionlimited aggregation [15] leads to the fractal aggregates with uniform corona for the ablation in helium. A thickness gradient characterises the aggregation in argon as a consequence of particle concentration gradient toward the walls. In both cases, in proximity to the sample surface the corona is not

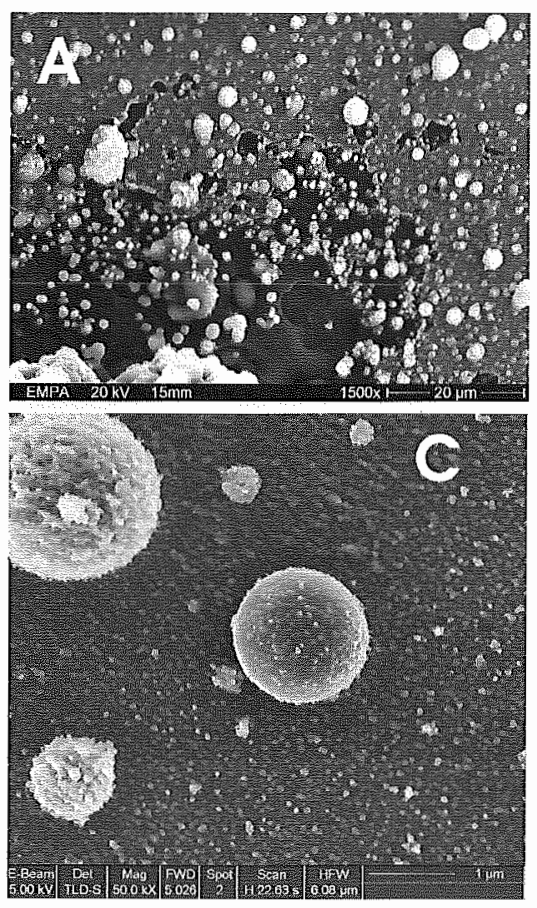

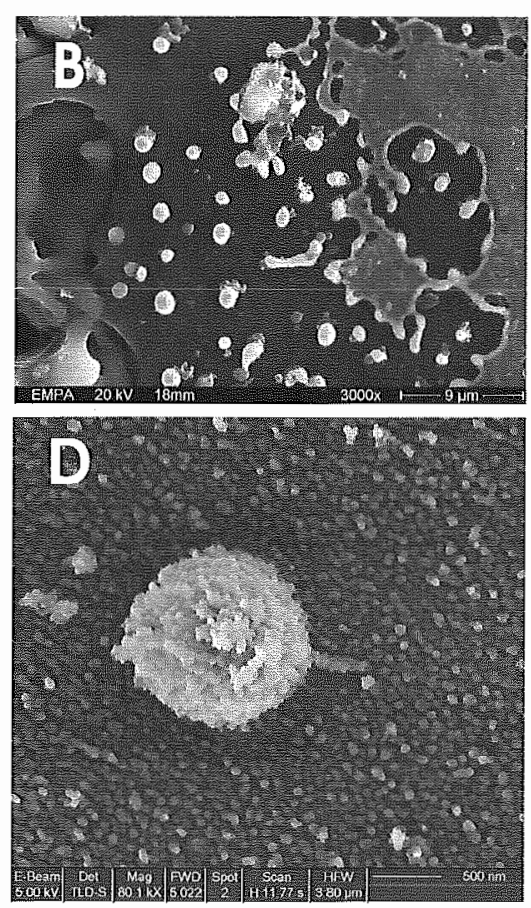

FIGURE 2 Overview of ablation products. See text for description 

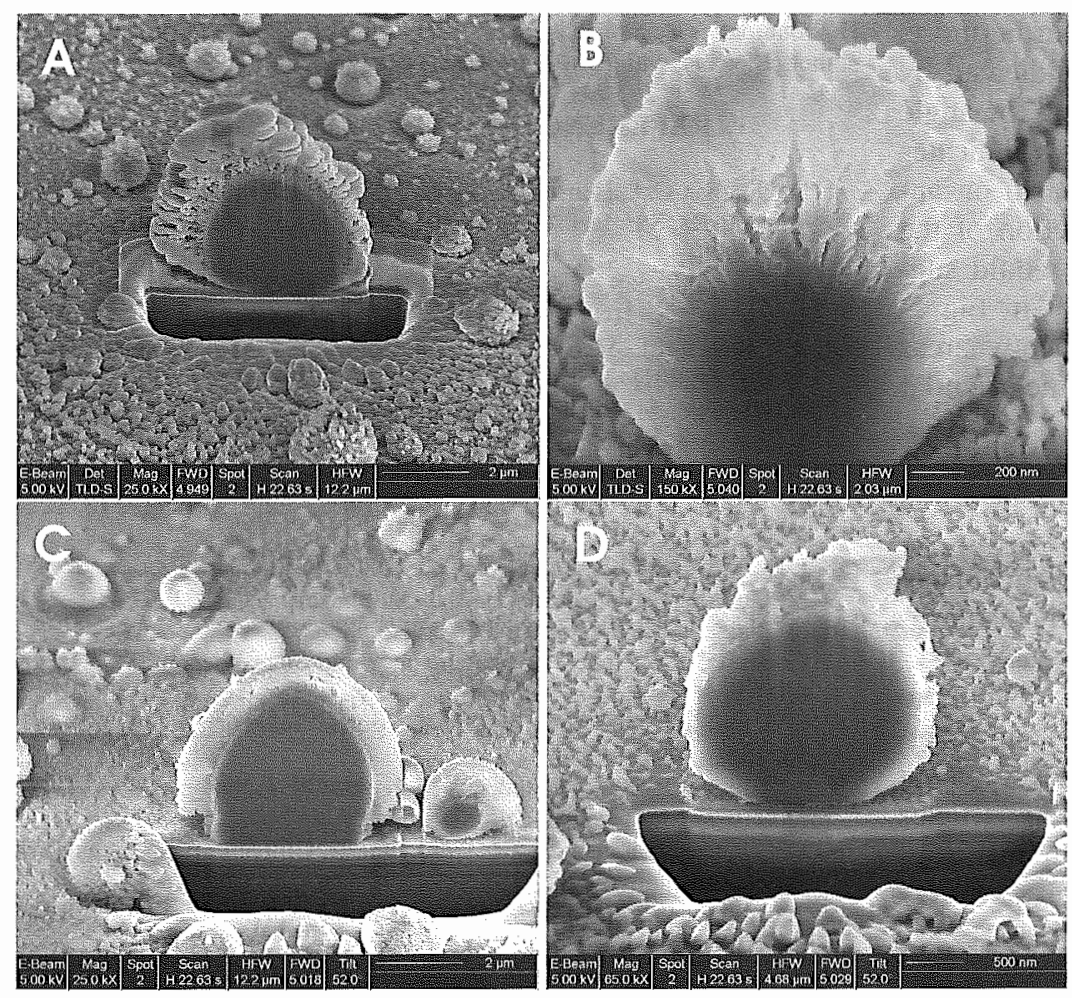

FIGURE 3 FIB cross-section of particles ablated in different ambient gases. $\mathbf{a}$ air, $\mathbf{b}$ argon, $\mathbf{c}$ helium, $\mathbf{d}$ nitrogen

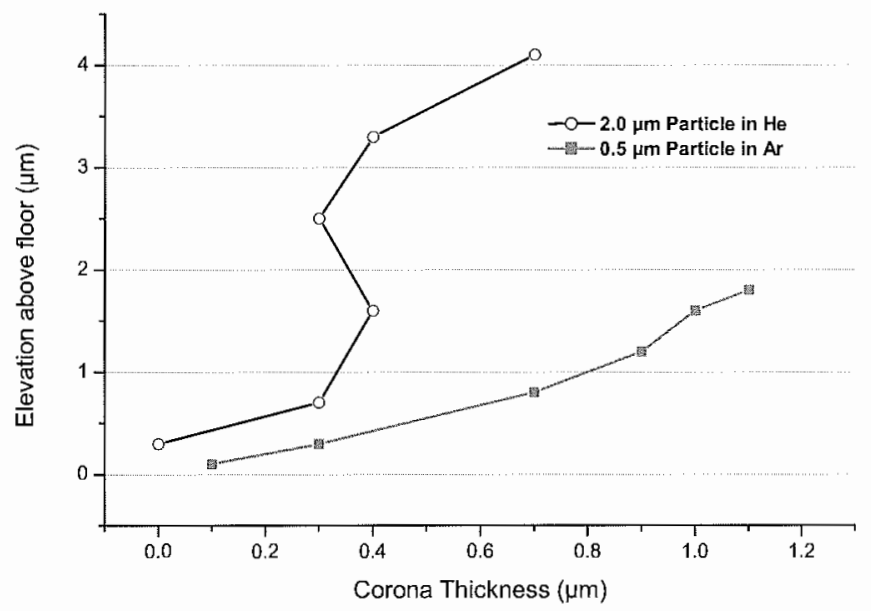

FIGURE 4 Radial thickness of the sheath layer (corona) as a function of elevation from the floor in argon and helium

developed, due to this 'wall effect' exerted by the sample surface on the aerosol concentration. Figure 4 shows the radial thickness of the corona at several elevations above the sample surface, in argon and helium, showing that in argon a factor of three larger gradient of the particle concentration profile is present with respect to helium.

The observations made would suggest that particle loss inside the sample chamber is a systematic phenomenon. Large cells enhance the loss of particles and deplete the signal intensity. Since particle transport efficiency is a size-dependent process [16], and since nano and micro particles are chemically heterogeneous, then analyte-dependent signal deviation is induced by particle fractionation.

Figure 5 shows a particle sliced with FIB into a 100-nmthin lamella, and this thin lamella was then used for transmis-

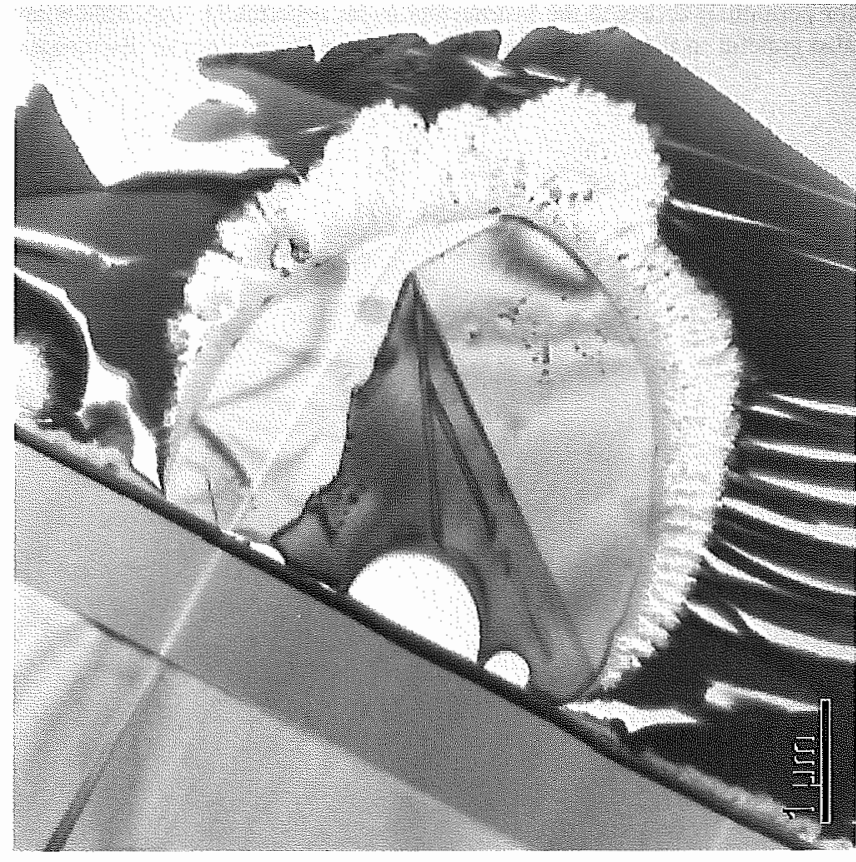

FIGURE 5 TEM lamella of a particle produced in helium that has trapped a gas bubble during settling. See text for description

sion electron microscopy (TEM) [17-19]. In order to stabilize the particle to the sample floor, GIS was used (black embedding mass). The crystallographic characteristics of the particle have been investigated by selected area electron diffiaction (SAED) patterns obtained at different location on the lamella. Multiple crystals could be recognized in the particle core, which are however different orientations of the same lattice. A crystallization sequence, from a precocious euhedral individual to a tardive "filler" could be identified 
from geometric relations of the crystal edges. Furthermore, the lattice of the tardive crystal is distorted as indicated by an "optical wave" of the reflexes obtained rotating the angle of the lamella relative to the electron beam. This indicates that heat removal was more rapid on one part than on another, which could be caused by the flow direction of the gas in the chamber. The texture of the corona would suggest that the gas was flowing from right to left in Fig. 5, because on the upstream side the corona is uniform whereas on the downstream side turbulence has produced the irregular growth.

\section{Conclusions}

Large variability in the primary mechanism of laser ablation particle formation and heterogeneity in the shape as well as in the composition were observed in the case of silicon. Post-sampling nano-micro particle aggregation led to secondary particulate whose outer surface growth rate is significantly influenced by the ambient gas. Surface development and internal crystalline features of the laser-induced particles were documented. Signal drift in analytical measurement signals is surely influenced by particulate heterogeneity.

ACKNOWLEDGEMENTS U. Klotz is acknowledged for valuable support with the TEM instrument. U. Sennhauser is acknowledged for permitting access to the instruments in his department. The authors are also grateful to P. Lienemann and M. Trottmann for productive discussions.
H. Vonmont is acknowledged for supporting the post-doc project of one author (Bleiner), with EMPA dossier number 840744.

\section{REFERENCES}

1 D. Günther, C.A. Heinrich: J. Anal. Atom. Spectrom. 14, 1369 (1999)

2 T.E. Jeffries, S.E. Jackson, H.P. Longerich: J. Anal. Atom. Spectrom. 13, 935 (1998)

3 J.J. Gonzalez, S.S. Mao, X.L. Mao, J. Roy, R.E. Russo: J. Anal. Atom. Spectrom. 17, 1108 (2002)

4 R.E. Russo, X.L. Mao, S.S. Mao, J.J. Gonzalez: J. Anal. Atom. Spectrom 17, $1072(2002)$

5 V. Margetic, M. Bolshov, A. Stockhaus, K. Niemax, R. Hergenroeder: J. Anal. Atom. Spectrom. 16, 616 (2001)

6 L. St-Onge: J. Anal. Atom. Spectrom 17, 1083 (2002)

7 M. Guillong, I. Horn, D. Güinther: J. Anal. Atom. Spectrom. 18, 1224 (2003)

8 I. Horn, D. Günther: Appl. Surf. Sci. 207, 144 (2003)

9 M. Guillong, D. Guenther: J. Anal. At. Spectrom. 17, 831 (2002)

10 D. Bleiner: ETH Dissertation 14665

11 C. Eisele, C.E. Nebel, M. Stutzmann: Solid-State Phenom. 80-81, 205 (2001)

12 P.M. Outridge, W. Doherty, D.C. Gregoire: Spectrochim. Acta, Part B 51, 1451 (1997)

13 M. Ullmann, S.K. Friedlander, A. Schmidt-Ott: J. Nanopart. Res. 4, 499 (2002)

14 D. Bleiner, P. Lienemann, M. Trottmann, A. Ulrich: Canad. J. Anal. Sci. Spect., Special issue ICASS (2003)

15 T.A. Witten, J. Sander, L.M. Sander: Phys. Rev. Lett. 47, 1400 (1981)

16 M.A. Gilbertson, I. Eanes: Powder Technol. 131, 197 (2003)

17 A.E.M. De Veirman: Mater. Sci. Eng., B 102, 63 (2003)

18 J.C. Reiner, P. Gasser, U. Sennhauser: Microel. Reliab. 42, 1753 (2002)

19 Ph. Gasser, U. Klotz, F.A. Kahlid, O. Beffort: Microse. Microanal. 10, 1 (2004) 